\title{
Effects of IncRNA ANRIL-knockdown on the proliferation, apoptosis and cell cycle of gastric cancer cells
}

\author{
XUEQIAN HU, TING LOU, CHUNYING YUAN, YONGSHENG WANG, \\ XIAOLONG TU, YI WANG and TINGSU ZHANG \\ Department of Oncology, Ningbo Municipal Hospital of Traditional Chinese Medicine, \\ Affiliated Hospital of Zhejiang Chinese Medical University, Ningbo, Zhejiang 315000, P.R. China
}

Received February 22, 2021; Accepted June 2, 2021

DOI: $10.3892 / \mathrm{ol} .2021 .12882$

\begin{abstract}
Gastric cancer is one of the most common types of malignant tumor of the gastrointestinal tract worldwide. Cisplatin (DDP) is a commonly used chemotherapeutic drug in the clinic; however, the resistance of gastric cancer cells to DDP limits its efficacy. In the present study, drug-resistant gastric cancer cell lines were constructed using the stepwise continuous selection method, and the relative expression levels of long non-coding RNA (lncRNA) CDKN2B antisense RNA 1 (ANRIL) and microRNA (miR)-181a-5p were detected using reverse transcription-quantitative PCR. The knockdown of lncRNA ANRIL and miR-181a-5p expression was performed by transfection with shRNA-ANRIL and an miR-181a-5p inhibitor, respectively. Cellular proliferation and sensitivity to DDP were assessed using Cell Counting Kit-8 analysis. Cell apoptosis and cell cycle distribution were assessed using flow cytometry and western blotting. The binding relationships between ANRIL, miR-181a-5p and cyclin G1 (CCNG1) were verified using a dual luciferase reporter assay. The results revealed that the expression levels of miR-181a-5p were downregulated in all drug-resistant cell lines. ANRIL-knockdown inhibited cellular proliferation, and promoted apoptosis and cell cycle arrest; however, following the knockdown of miR-181a-5p, the inhibition of cell cycle arrest was alleviated. Notably, miR-181a-5p, ANRIL and CCNG1 were found to have targeting relationships. In conclusion, the findings of the present study suggested that knocking down the expression of ANRIL inhibited cellular proliferation, and promoted apoptosis and cell cycle arrest. Furthermore, its downstream target,
\end{abstract}

Correspondence to: Dr Tingsu Zhang, Department of Oncology, Ningbo Municipal Hospital of Traditional Chinese Medicine, Affiliated Hospital of Zhejiang Chinese Medical University, 819 North Liyuan Road, Haishu, Ningbo, Zhejiang 315000, P.R. China

E-mail: zhangtingsu@163.com

Key words: gastric cancer, resistance, long non-coding RNA CDKN2B antisense RNA 1, microRNA-181a-5p, cyclin G1
miR-181a-5p, inhibited the proliferation of drug-resistant cells and enhanced their sensitivity to DDP.

\section{Introduction}

Gastric cancer is one of the most common types of malignant tumor in the gastrointestinal tract worldwide. Its morbidity and mortality are ranked fourth and fifth, respectively, amongst all cancer types globally $(1,2)$. The development of gastroscopy technology has significantly improved the diagnostic and cure rates of patients with early gastric cancer. Except for a small number of early gastric cancer cases with small lesion areas, gastroscopy is suitable for endoscopic treatment. For other cases of gastric cancer, surgery and chemotherapy remain the primary treatment options $(3,4)$. Cisplatin (DDP) is a commonly used chemotherapeutic drug in the clinic; however, the insensitivity of gastric cancer cells to DDP limits its efficacy (5). Therefore, further in-depth studies into the molecular mechanisms of gastric cancer and cellular resistance are required to identify novel therapeutic targets and implement individualized treatment strategies for gastric cancer.

Long non-coding RNAs (lncRNA) are a type of non-coding RNA of $>200$ nucleotides in length, which contain neither a start nor stop codon (6). LncRNAs have been revealed to play vital roles in multiple cellular processes, such as gene expression regulation, genome imprinting and chromatin packaging, and during various stages, including cellular differentiation and embryonic development (7). IncRNA CDKN2B antisense RNA 1 (ANRIL) is an antisense non-coding RNA (8), and a 403-kb deletion in the gene was first identified in patients with melanoma and tumors of the nervous system (9). ANRIL is expressed in a variety of normal tissues, with the highest expression levels found in ovarian tissue and the lowest in muscle tissue (10). In addition, previous studies have reported that the expression levels of ANRIL were significantly upregulated in lung cancer, liver cancer and esophageal squamous cell carcinoma, which suggests that ANRIL may function as an oncogene $(11,12)$.

It is well established that lncRNAs can regulate microRNA (miRNA/miR) expression and thereby influence tumor progression (13). A large number of studies have reported that miRNAs bind to target genes to regulate the occurrence and development of numerous tumor types (14). Previous research 
has also shown that the expression of miR-181a-5p was downregulated in gastric cancer and that the overexpression of miR-181a-5p inhibited cellular proliferation (15).

Drug resistance in gastric cancer cells limits the efficacy of drugs in the clinic. The present study aimed to determine the effects of ANRIL and miR-181-5p on DDP-sensitive and -resistant gastric cancer cells, as well as the underlying mechanisms of action. The results may provide novel targets to overcome drug resistance in gastric cancer.

\section{Materials and methods}

Cell lines and culture. Normal gastric epithelial cells (GES1) and gastric cancer cell lines (HGC-27, AGS, HSC-39 and FU97) were purchased from the American Type Culture Collection. DDP (purity $>99.99 \%$ ) was purchased from Merck KGaA. Cells were cultured in DMEM (Gibco; Thermo Fisher Scientific, Inc.) supplemented with $10 \%$ FBS (Gibco; Thermo Fisher Scientific, Inc.), and maintained at $37^{\circ} \mathrm{C}$ with $5 \% \mathrm{CO}_{2}$. Cells were exposed to increasing concentrations of DDP to establish DDP-resistant gastric cancer cells. Briefly, cells in the logarithmic growth phase were first cultured with $0.05 \mu \mathrm{g} / \mathrm{ml}$ DDP. Following a week, the surviving cells were subsequently cultured with increasing concentrations of DDP until the cells could be stably subcultured in medium containing $0.5 \mu \mathrm{g} / \mathrm{ml}$ DDP. Each time the concentration of DDP was increased by 1.2 or 1.5 times, the process experienced 9 times of concentration increase and six months in total.

Reverse transcription-quantitative PCR (RT-qPCR). For mRNA expression analysis, total RNA was extracted from cultured cells using TRIzol ${ }^{\circledR}$ reagent (Invitrogen; Thermo Fisher Scientific, Inc.). Total mRNA was reverse transcribed into cDNA using the FSQ-101 reverse transcription system kit (Toyobo Life Science), and qPCR was subsequently performed using the QuantiTect SYBR-Green PCR kit (Qiagen, Inc.). For miRNA expression analysis, total RNA was extracted from cells using the fast microRNA isolation kit (BioTeke Corporation). Reverse transcription and qPCR were subsequently performed using the miScript RT kit and miScript SYBR Green qPCR kit (GeneCopoeia, Inc.), respectively, according to the manufacturers' protocols. The qPCR thermocycling conditions were as follows: Pre-denaturation at $95^{\circ} \mathrm{C}$ for $30 \mathrm{sec}$, followed by 40 cycles of denaturation at $95^{\circ} \mathrm{C}$ for $5 \mathrm{sec}$, annealing at $60^{\circ} \mathrm{C}$ for $30 \mathrm{sec}$, and extension at $72^{\circ} \mathrm{C}$ for $10 \mathrm{sec}$. The primers used for qPCR are listed in Table I. Expression levels of mRNA and miRNA were quantified using the $2^{-\Delta \Delta \mathrm{Cq}}$ method (16) and normalized to that of GADPH or U6, respectively.

Transfection. Cells were digested with $0.25 \%$ trypsin and seeded into a 6 -well plate at a density of $2 \times 10^{5}$ cells/well, which was then incubated at $37^{\circ} \mathrm{C}\left(5 \% \mathrm{CO}_{2}\right)$ for $24 \mathrm{~h}$. The cells were subsequently transfected with $100 \mathrm{nM}$ miR-181a-5p inhibitors, inhibitor-negative control (NC), short hairpin RNA (shRNA)-ANRIL vectors and scrambled shRNA-NC (all Shanghai GenePharma Co., Ltd.) using Lipofectamine ${ }^{\circledR}$ 2000 reagent (Invitrogen; Thermo Fisher Scientific, Inc.) for $24 \mathrm{~h}$ at $37^{\circ} \mathrm{C}$. shRNA-ANRIL-1 and shRNA-ANRIL-2 were incorporated into the same vector, and both sequences were provided by GenePharma Co., Ltd. Following transfection for $24 \mathrm{~h}$, the cells were utilized for subsequent experiments.

Cell Counting Kit-8 (CCK-8) assay. Transfected cells in the logarithmic growth phase were digested with $0.25 \%$ trypsin, seeded into a 96 -well plate at a density of $5 \times 10^{4}$ cells/well, and incubated at $37^{\circ} \mathrm{C}$ for $24 \mathrm{~h}$. Following incubation, $10 \mu \mathrm{l} \mathrm{CCK}-8$ reagent (Beyotime Institute of Biotechnology) was added to each well and the plate was incubated for a further hour. The optical density of each well was measured at a wavelength of $450 \mathrm{~nm}$ using a microplate reader (Thermo Fisher Scientific, Inc.).

Flow cytometry. For apoptosis analysis, cells were digested with $0.25 \%$ trypsin and washed twice with PBS. Cells $\left(1 \times 10^{5}\right.$ per sample) were subsequently centrifuged at $150 \mathrm{x}$ g, resuspended in binding buffer, and then incubated with Annexin V-FITC in the dark at room temperature for $30 \mathrm{~min}$. The cells were then incubated at room temperature with propidium iodide (PI) in the dark for $5 \mathrm{~min}$. For cell cycle distribution analysis, following centrifugation at $150 \mathrm{x} g$ and resuspension in PBS, the cells were incubated with PI staining solution (50 mg/l P1, $1 \mathrm{~g} / 1$ Triton X and $100 \mathrm{~g} / 1 \mathrm{RNase})$ in the dark at $4^{\circ} \mathrm{C}$ for $30 \mathrm{~min}$. Data were analyzed using FlowJo (v7.6.1; FlowJo, LLC) following flow cytometry on a FACSCalibur flow cytometer (BD Biosciences).

Western blotting. Total protein was extracted from cells using RIPA lysis (Beyotime Institute of Biotechnology), and quantified using a BCA assay kit (Beyotime Institute of Biotechnology). Protein samples $(25 \mu \mathrm{g})$ were separated via $10 \%$ SDS-PAGE, transferred onto PVDF membranes, and then blocked with 5\% BSA (Thermo Fisher Scientific, Inc.) at room temperature for $1 \mathrm{~h}$. The membranes were subsequently incubated with the following primary antibodies at $4^{\circ} \mathrm{C}$ overnight: Anti-p53 (cat. no. MA5-16387; 1:1,000), anti-Bax (cat. no. PA5-11378; 1:2,000), anti-Bcl-2 (cat. no. PA5-27094; 1:1,000), anti-cleaved caspase-3 (cat. no. PA5-114687; 1:1,000), anti-cyclin G1 (CCNG1; cat. no. PA5-36050; 1:1,000), anti-cyclin D1 (CCND1; cat. no. PA5-32373; 1:1,000), anti-CDK4 (cat. no. PA5-27827; 1:1,000) and anti-GAPDH (cat. no. MA1-16757; 1:2,000) (all Thermo Fisher Scientific, Inc.). Following primary antibody incubation, the membranes were incubated with an HRP-conjugated goat anti-rabbit antibody (cat. no. G-21234; Thermo Fisher Scientific, Inc.; 1:100,000) at room temperature for $1 \mathrm{~h}$. Protein bands were visualized using chemiluminescent reagents and densitometric analysis was performed using ImageJ version 1.52 software (National Institutes of Health).

Dual-luciferase reporter assay. ANRIL and CCNG1 wild-type (WT) and mutant-type (MUT) pmiRGlo luciferase expression vectors containing miR-181-5p binding sites were constructed by Shanghai GenePharma Co., Ltd., and co-transfected with NC mimic or miR-181-5p mimic into cells $\left(5 \times 10^{5}\right.$ cells/well) plated into 96 -well plates using Lipofectamine ${ }^{\circledR} 2000$ reagent (Invitrogen; Thermo Fisher Scientific, Inc.). The Dual Luciferase Reporter Gene Assay kit (cat. no. RG027; Beyotime Institute of Biotechnology) was used according to the manufacturer's instructions. The relative luciferase activity was measured after $48 \mathrm{~h}$ and normalized to the activity of Renilla luciferase. Sequences used to regulate endogenous miR-181a-5p were listed in Table II. 
Table I. Sequences of the primers for qPCR.

\begin{tabular}{ll}
\hline Gene & \\
\hline CCNG1 & \multicolumn{1}{c}{ Sequence } \\
ANRIL & Forward: 5'-AATGAAGGTACAGCCCAAGCA-3' \\
miR-181a-5p & Reverse: 5'-GCTTTGACTTTCCAACACACC-3' \\
& Forward: 5'-CTCCAGACAGGGTCTCACTC-3' \\
GAPDH & Reverse: 5'-GGAAATTCCTAGCTCCGTAA-3' \\
& Forward: 5'-GCCGAACATTCAACGCTGTCG-3' \\
U6 & Reverse: 5'-GTGCAGGGTCCGAGGT-3' \\
& Forward: 5'-AAATCCCATCACCATCTTCCAG-3' \\
& Reverse: 5'-GAGTCCTTCCACGATACCAAAGTTG-3' \\
& Forward: 5'-ATTGGAACGATACAGAGAAGATT-3' \\
& Reverse: 5'-GGAACGCTTCACGAATTTG-3'
\end{tabular}

Table II. Sequences used to regulate endogenous miR-181a-5p.

Gene

miR-181a-5p mimic-

mimic NC

miR-181a-5p inhibitor

inhibitor NC
Sequence

Forward: 5'-AACAUUCAACGCUGUCGGUGAGU-3'

Reverse: 5'-UUUUGUAAGUUGCGACAGCCACU-3'

Forward: 5'-UUCUCCGAACGUGUCACGUTT-3'

Reverse: 5'-TTAAGAGGCUUGCACAGUGCA-3'

5'-ACUCACCGACAGCGUUGAAUGUU-3'

5'-CAGUACUUUUGUGUAGUACAA-3'
Bioinformatics analysis. The Encyclopedia of RNA Interactomes (ENCORI) (17) was used to predict miRNAs that bind to ANRIL, and TargetScan, PicTar and miRanda were used to predict target genes that bind to miRNA. ENCORI (http://starbase.sysu.edu.cn/) is an open-source platform for studying the interactions between various RNAs. 'CDKN2B AS' was entered into the webpage and the associated miRNAs were displayed. TargetScan (18) (http://www.targetscan.org/) predicts the biological targets of miRNAs by searching for the presence of conserved 8mer and 7 mer sites that match the seed region of each miRNA. PicTar (19) (https://pictar.mdc-berlin.de/) uses an algorithm to identify the microRNA targets. miRanda (20) (http://www.microrna.org/microrna/home.do) is an online database for miRNA target prediction and functional annotations. miR-181a-5p was entered and the results of the three databases were comprehensively considered.

Statistical analysis. Statistical analysis was performed using GraphPad Prism 8.0 software (GraphPad Software, Inc.) and quantitative data are presented as the mean \pm SD. Statistical differences between two groups were determined using unpaired Student's t-test, while one-way ANOVA and Tukey's post hoc test were used to determine statistical differences between multiple groups. $\mathrm{P}<0.05$ was considered to indicate a statistically significant difference.

\section{Results}

Construction of drug-resistant cell lines and detection of relative CCNG1, ANRIL and miR-181a-5p expression levels.
Using the ENCORI database, miR-181a-5p was predicted to share a targeting relationship with ANRIL and CCNG1 via TargetScan, PicTar and miRanda. In particular, the 3'-untranslated region (UTR) region of miR-181a-5p was found possess a binding site for ANRIL. Furthermore, the 3'-UTR region of CCNG1 was found to share binding sites with miR-181a-5p, which suggested that CCNG1 may be a potential target gene of miR-181a-5p. Multiple DDP-resistant gastric cancer cell lines were constructed, and the expression levels of CCNG1 in normal and DDP-resistant cells were analyzed using RT-qPCR. Compared with GES1 cells, CCNG1 expression levels were dysregulated in DDP-sensitive cell lines $\left(^{* *} \mathrm{P}<0.01\right.$ and $\left.{ }^{* * *} \mathrm{P}<0.001\right)$. Notably, the expression levels of CCNG1 in DDP-resistant cell lines were upregulated compared with those of the GES1 cell line $\left({ }^{* * *} \mathrm{P}<0.001\right.$; Fig. $\left.1 \mathrm{~A}\right)$, and CCNG1 expression was upregulated to the greatest extent in HGC-27 and FU97 DDP-resistant cell lines. The expression levels of ANRIL and miR-181a-5p were also analyzed using RT-qPCR, both of which were dysregulated in DDP-sensitive cells; however, ANRIL expression was upregulated and miR-181a-5p expression was downregulated in drug-resistant cells $\left({ }^{*} \mathrm{P}<0.05\right.$, ${ }^{* *} \mathrm{P}<0.01$ and $^{* * *} \mathrm{P}<0.001$; Fig. 1B and C). For HGC-27 and FU97 cell lines, the differences in expression between drug-resistant and sensitive cell lines were more apparent; therefore, these two cell lines were used for subsequent experimentation.

Proliferation of gastric cancer cells and sensitivity to DDP. Cells were transfected with miR-181a-5p inhibitors and shRNA-ANRIL vectors, and RT-qPCR was then used to analyze transfection efficiency. In both the HGC-27 and FU97 sensitive 
A

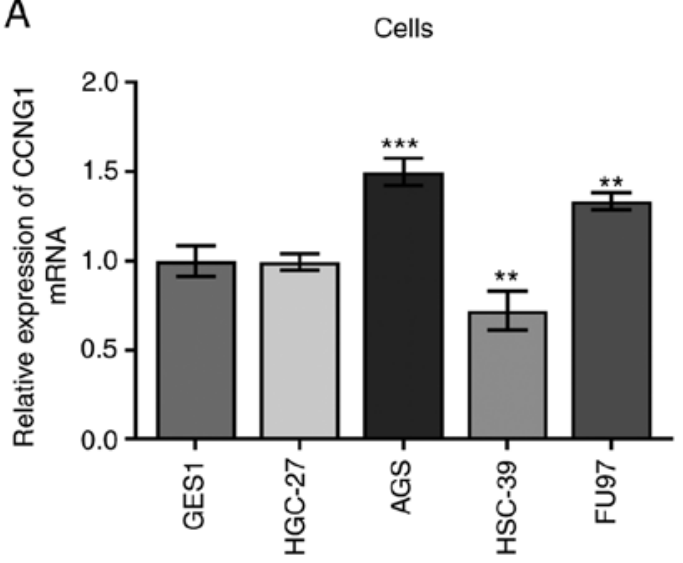

B

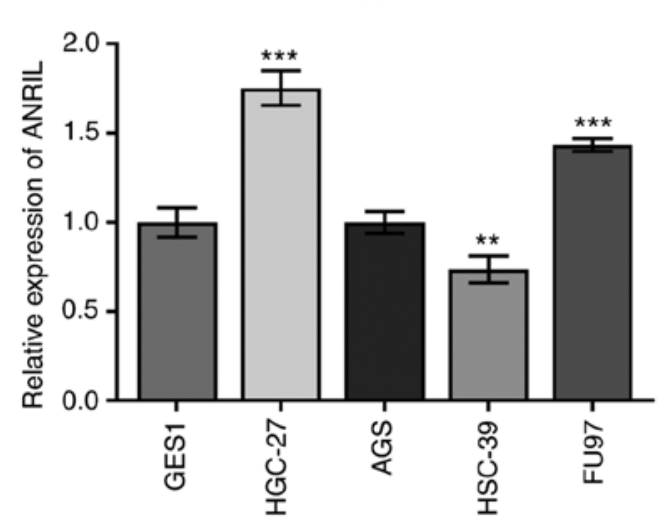

C

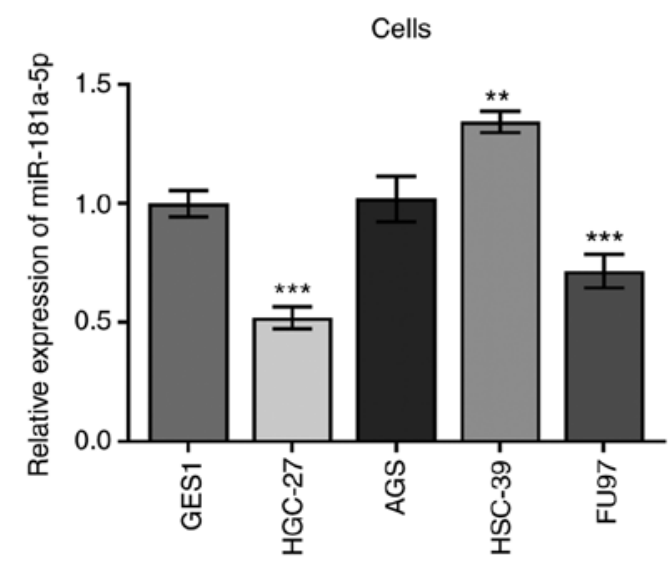

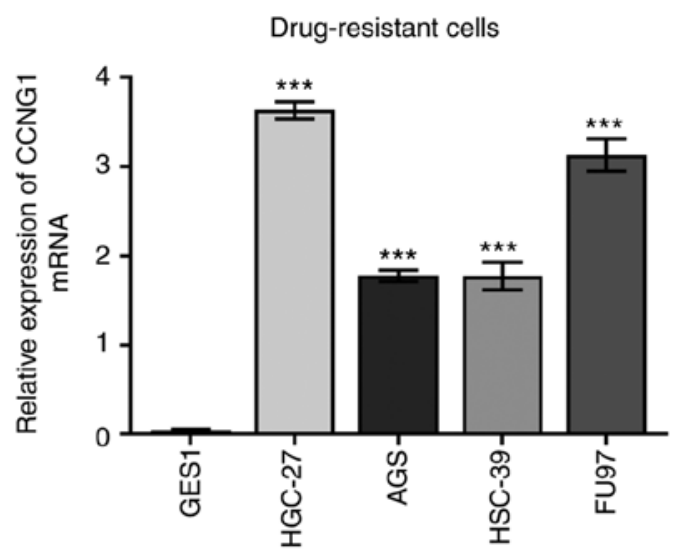

Drug-resistant cells

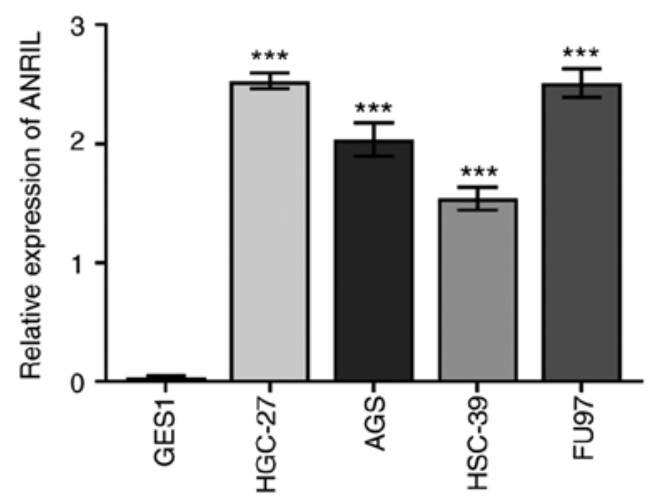

Drug-resistant cells

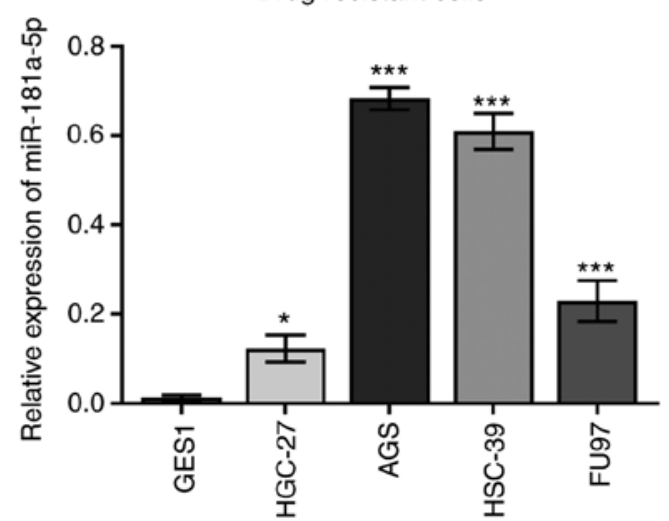

Figure 1. Expression levels of CCNG1, IncRNA-ANRIL and miR-181a-5p in cisplatin-sensitive and -resistant cell lines. Expression levels of (A) CCNG1, (B) lncRNA-ANRIL and (C) miR-181a-5p in gastric GES1 epithelial cells and HGC-27, AGS, HSC-39 and FU97 gastric cancer cell lines, and their associated drug-resistant lines. ${ }^{*} \mathrm{P}<0.05,{ }^{* *} \mathrm{P}<0.01$ and ${ }^{* * *} \mathrm{P}<0.001$ vs. GES1 cells; $\mathrm{n} \geq 3$. CCNG1, cyclin G1; IncRNA, long non-coding RNA; ANRIL, CDKN2B antisense RNA 1; miR, microRNA.

and DDP-resistant cell lines, compared with the inhibitor $\mathrm{NC}$, the expression levels of miR-181-5p were significantly downregulated in the miR-181-5p inhibitor groups $\left({ }^{\# \# \#} \mathrm{P}<0.001\right)$, with the greatest effect observed in cells transfected with miR-181a-5p inhibitor-1 compared with miR-181a-5p inhibitor-2 (Fig. 2A). In addition, the decrease in ANRIL expression was more significant when cells were transfected with shRNA-ANRIL-1 compared with shRNA-ANRIL-2 ( ${ }^{\# \#} \mathrm{P}<0.001$; Fig. 2B). Therefore, miR-181a-5p inhibitor-1 and shRNA-ANRIL-1 were selected for use in subsequent experiments.
Cells were then divided into five groups: i) Control; ii) shRNA-NC; iii) shRNA-ANRIL;iv) shRNA-ANRIL + inhibitor NC; and v) shRNA-ANRIL + miR-181a-5p inhibitor. The proliferation of sensitive and DDP-resistant cell lines was subsequently detected using a CCK-8 assay. The proliferation of DDP-resistant cell lines was increased compared with sensitive cell lines in all groups. In addition, transfection with shRNA-ANRIL decreased cellular proliferation $\left({ }^{\# \# \#} \mathrm{P}<0.001\right)$, while upon co-transfection with the miR-181a-5p inhibitor, this decrease in proliferation was reversed $\left({ }^{\$ \$} \mathrm{P}<0.001\right.$; Fig. $\left.3 \mathrm{~A}\right)$. 

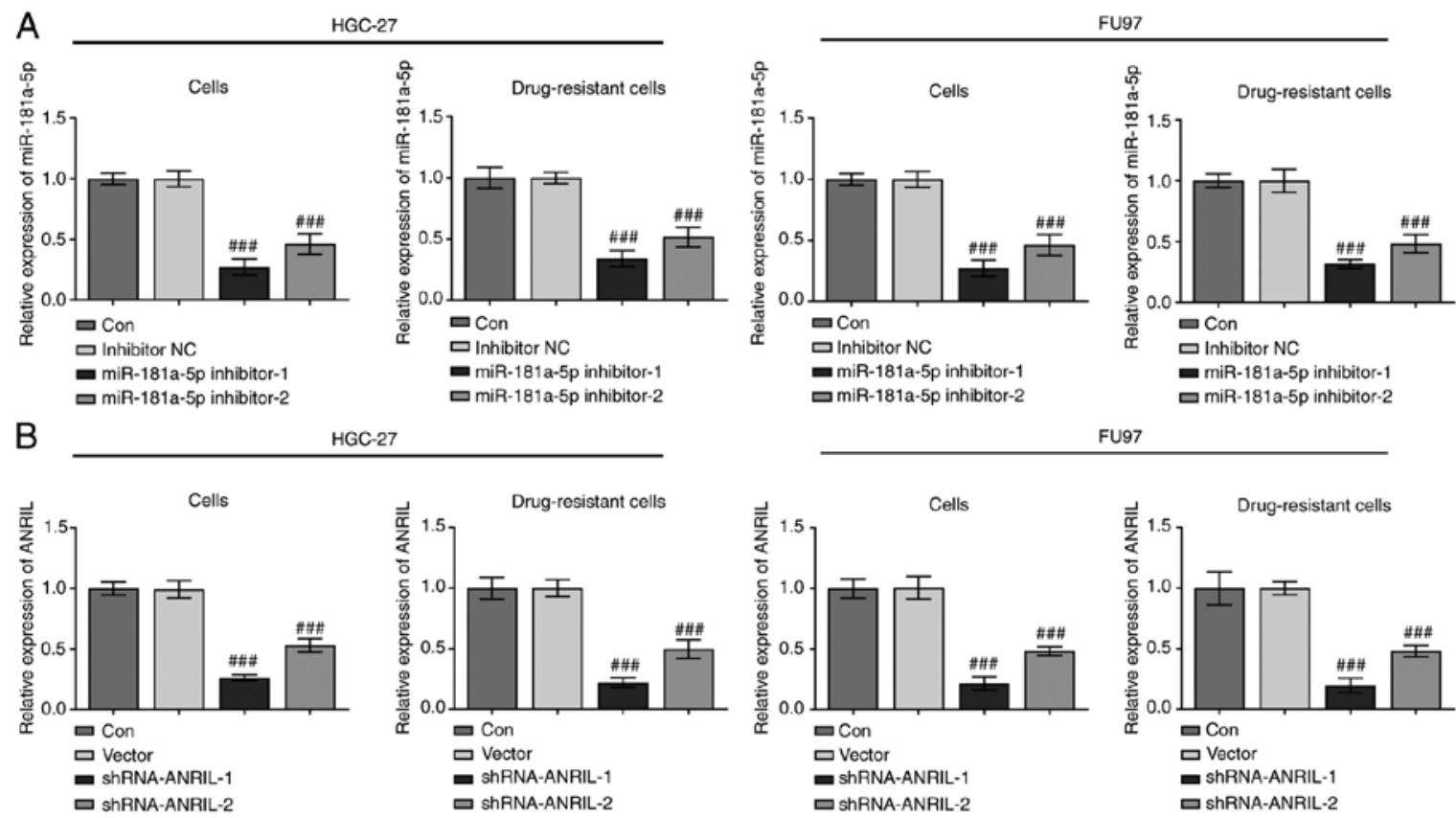

Figure 2. Transfection efficiency of two types of miR-181a-5p inhibitor and shRNA-ANRIL in gastric cancer cells. (A) Expression levels of miR-181a-5p in HGC-27 and FU97 cell lines transfected with two types of miR-181a-5p inhibitor. ${ }^{\# \# / P<0.001 ~ v s . ~ i n h i b i t o r ~ N C ; ~} \geq 3$. (B) Expression levels of ANRIL in HGC-27 and FU97 cell lines transfected with two types of shRNA-ANRIL. ${ }^{\# \#} \mathrm{P}<0.001$ vs. vector; $\mathrm{n} \geq 3$. miR, microRNA; shRNA, short hairpin RNA; ANRIL, CDKN2B antisense RNA 1; Con, control; NC, negative control.

A

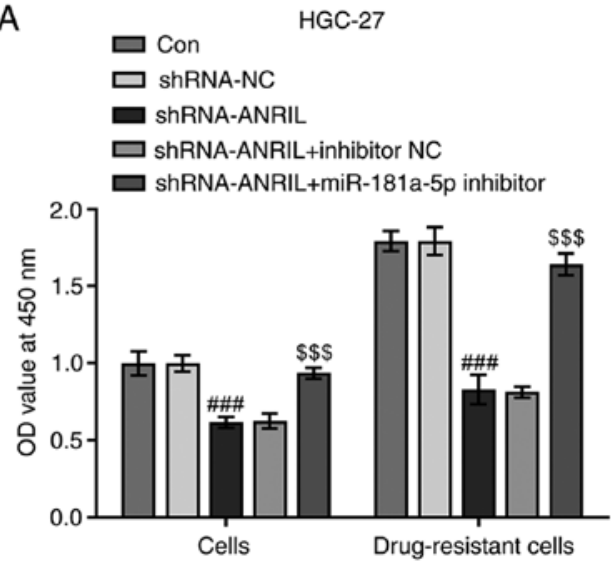

B

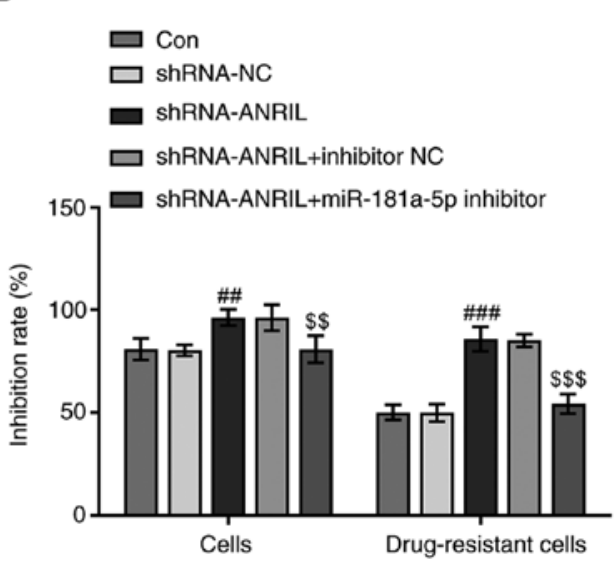

FU97

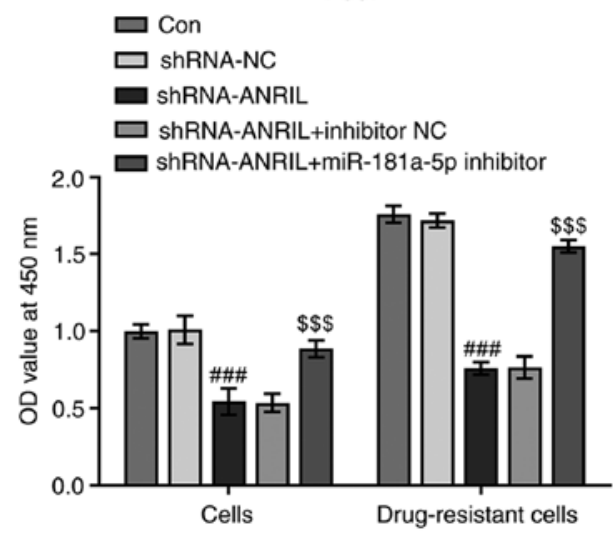

FU97

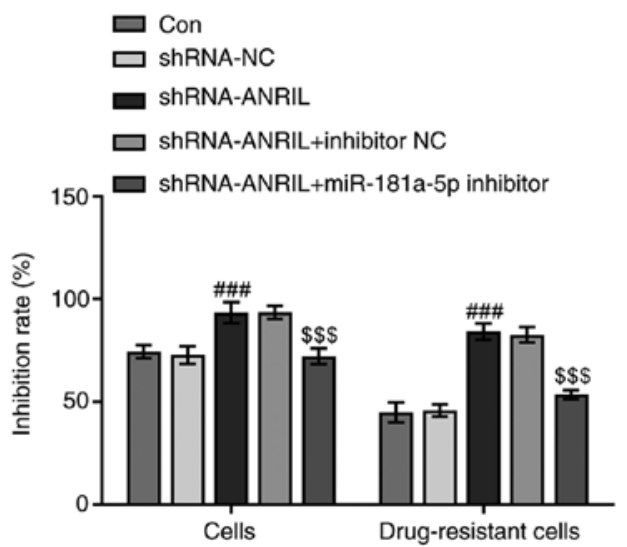

Figure 3. Proliferation and sensitivity of cells to DDP. (A) Cells were divided into five groups: Control, shRNA-NC, shRNA-ANRIL, shRNA-ANRIL + inhibitor NC and shRNA-ANRIL + miR-181a-5p inhibitor. OD value at $450 \mathrm{~nm}$ of HGC-27, FU97 and drug-resistant cell lines was determined. ${ }^{\# \#} \mathrm{P}<0.001 \mathrm{vs}$. shRNA-NC; ${ }^{\$ \$ \$} \mathrm{P}<0.001$ vs. shRNA-ANRIL + inhibitor NC; $\mathrm{n} \geq 3$. (B) Sensitivity to DDP is shown as the inhibition rate of HGC-27, FU97 and drug-resistant cell lines. ${ }^{\# \#} \mathrm{P}<0.01$ and ${ }^{\# \# \#} \mathrm{P}<0.001$ vs. shRNA-NC; ${ }^{\$ \$} \mathrm{P}<0.01$ and ${ }^{\$ \$ S} \mathrm{P}<0.001$ vs. shRNA-ANRIL + inhibitor NC; $\mathrm{n} \geq 3$. DDP, cisplatin; shRNA, short hairpin RNA; Con, control; NC, negative control; miR, microRNA; OD, optical density; ANRIL, CDKN2B antisense RNA 1. 
A
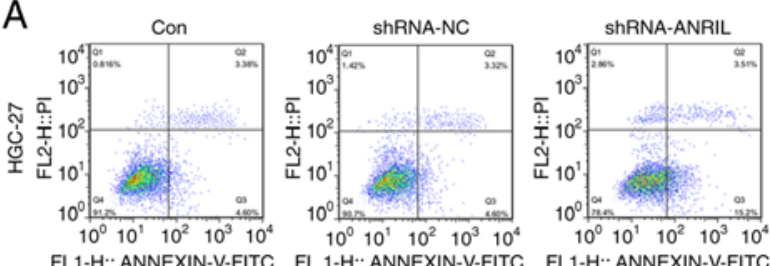

FL1-H:: ANNEXIN-V-FITC FL 1-H:: ANNEXIN-V-FITC FL1-H:: ANNEXIN-V-FITC

B
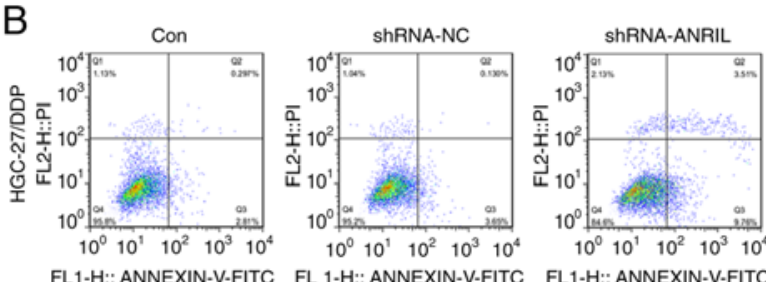

FL1-H:: ANNEXIN-V-FITC FL 1-H:: ANNEXIN-V-FITC FL1-H:: ANNEXIN-V-FITC
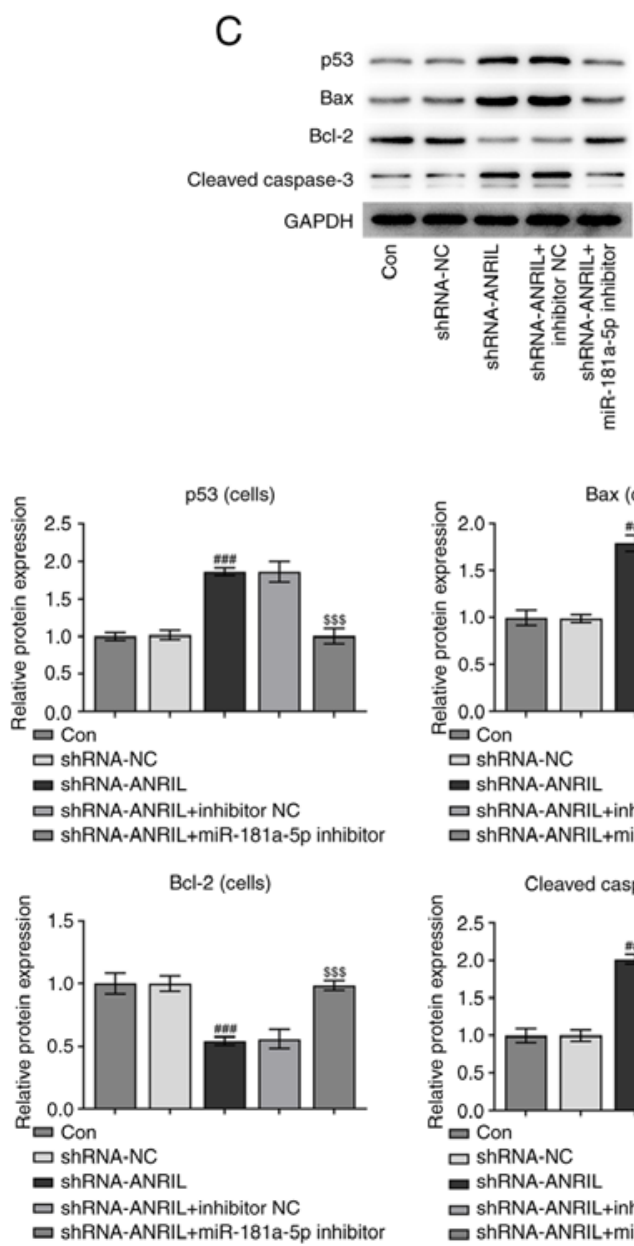
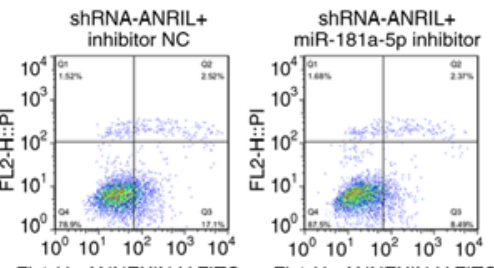

口 Con

ShRNA-NC

- shRNA-ANRIL

口 shRNA-ANRIL+inhibitor NC

- shRNA-ANRIL+miR-181a-5p inhibitor

FL1-H:: ANNEXIN-V-FITC FL1-H:: ANNEXIN-V-FITC

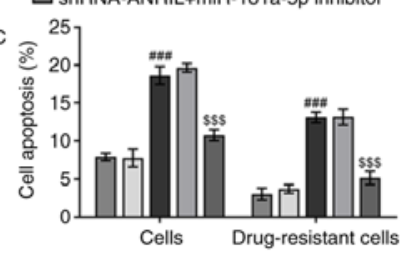

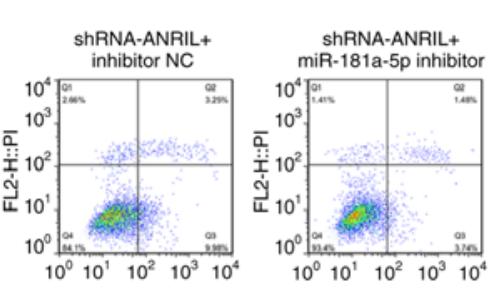

FL1-H:: ANNEXIN-V-FITC FL1-H:: ANNEXIN-V-FITC

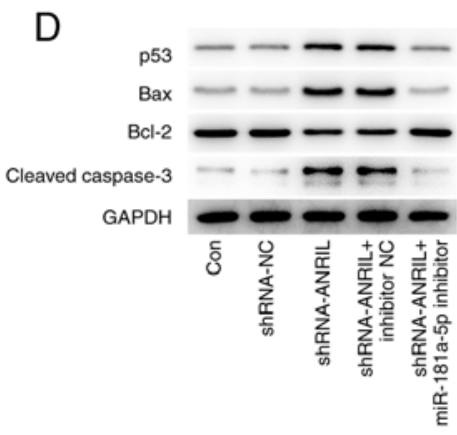

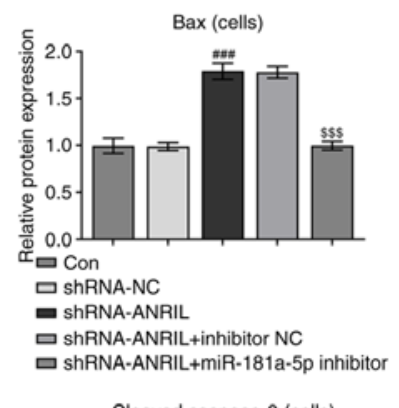
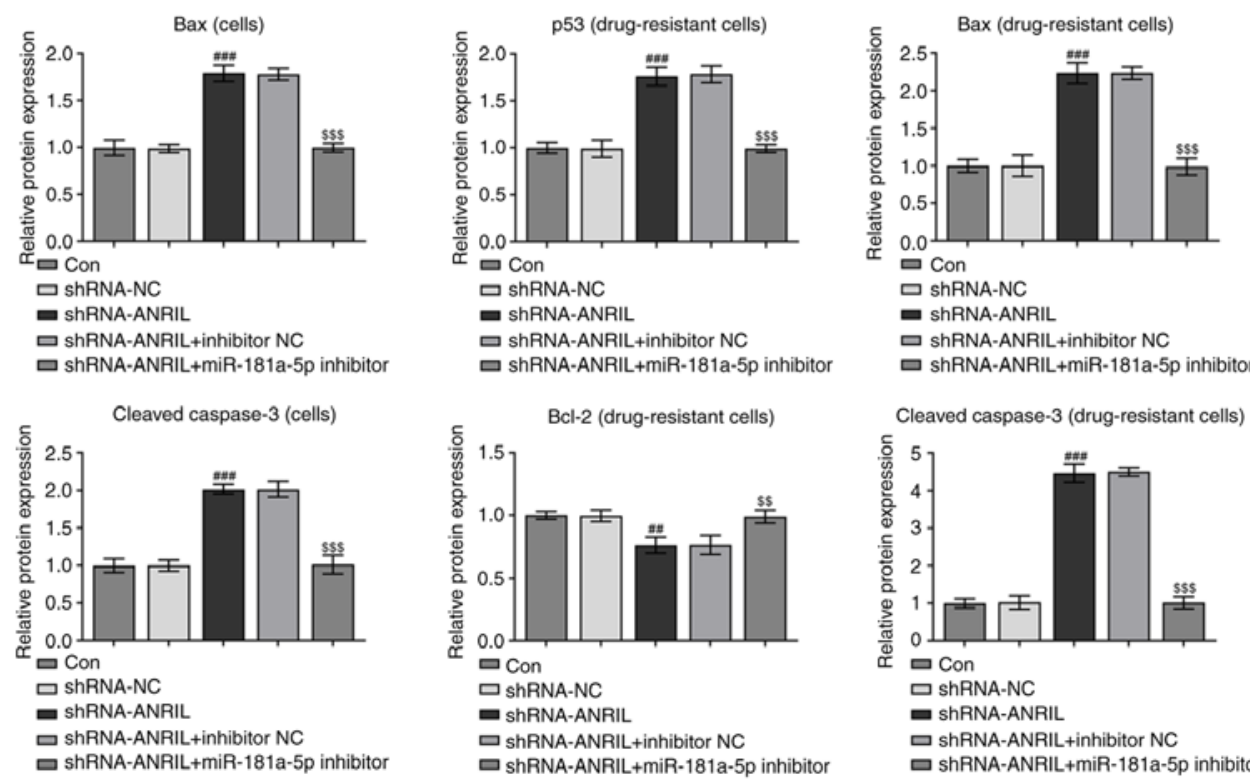

Cleaved caspase-3 (drug-resistant cells)

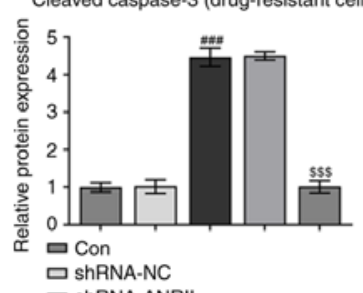

- ShRNA-ANR

口 shRNA-ANRIL+inhibitor NC

口 shRNA-ANRIL+miR-181a-5p inhibitor

Figure 4. Apoptosis of HGC-27 and drug-resistant cell lines. Apoptosis of (A) HGC-27 and (B) HGC-27 DDP-resistant cell lines was detected using flow cytometry. Expression of proteins associated with apoptosis in (C) HGC-27 and (D) HGC-27 DDP-resistant cell lines was analyzed using western blotting. ${ }^{\# \#} \mathrm{P}<0.01$ and ${ }^{\# \# \#} \mathrm{P}<0.001$ vs. shRNA-NC; ${ }^{\$ \$} \mathrm{P}<0.01$ and ${ }^{\$ \$ \$} \mathrm{P}<0.001$ vs. shRNA-ANRIL + inhibitor NC; $\mathrm{n} \geq 3$. shRNA, short hairpin RNA; Con, control; NC, negative control; ANRIL, CDKN2B antisense RNA 1; DDP, cisplatin.

These results suggested that ANRIL may promote gastric cell proliferation, while miR-181a-5p may inhibit proliferation. The sensitivity of cells in different groups to DDP was also detected using a CCK-8 assay. Following the knockdown of ANRIL, cell sensitivity increased $\left({ }^{\# \#} \mathrm{P}<0.01,{ }^{\# \# \#} \mathrm{P}<0.001\right)$; however, following co-transfection of the miR-181a-5p inhibitor, cell sensitivity was decreased $\left({ }^{\$ \$} \mathrm{P}<0.01,{ }^{\$ \$ \$} \mathrm{P}<0.001\right)$. This trend was more apparent in drug-resistant cell lines (Fig. 3B).
Detection of apoptosis. Apoptosis in the different groups was analyzed using flow cytometry. The knockdown of ANRIL in DDP-sensitive or -resistant cell lines increased the levels of apoptosis. Conversely, the subsequent co-transfection with the miR-181a-5p inhibitor reversed this trend $\left({ }^{(\# \#)} \mathrm{P}<0.001\right.$ and ${ }^{\$ \$ \$} \mathrm{P}<0.001$; Fig. 4A and $\left.\mathrm{B}\right)$. In addition, western blotting was used to analyze the expression levels of $\mathrm{p} 53, \mathrm{Bax}, \mathrm{Bcl}-2$ and cleaved caspase-3, which are all 

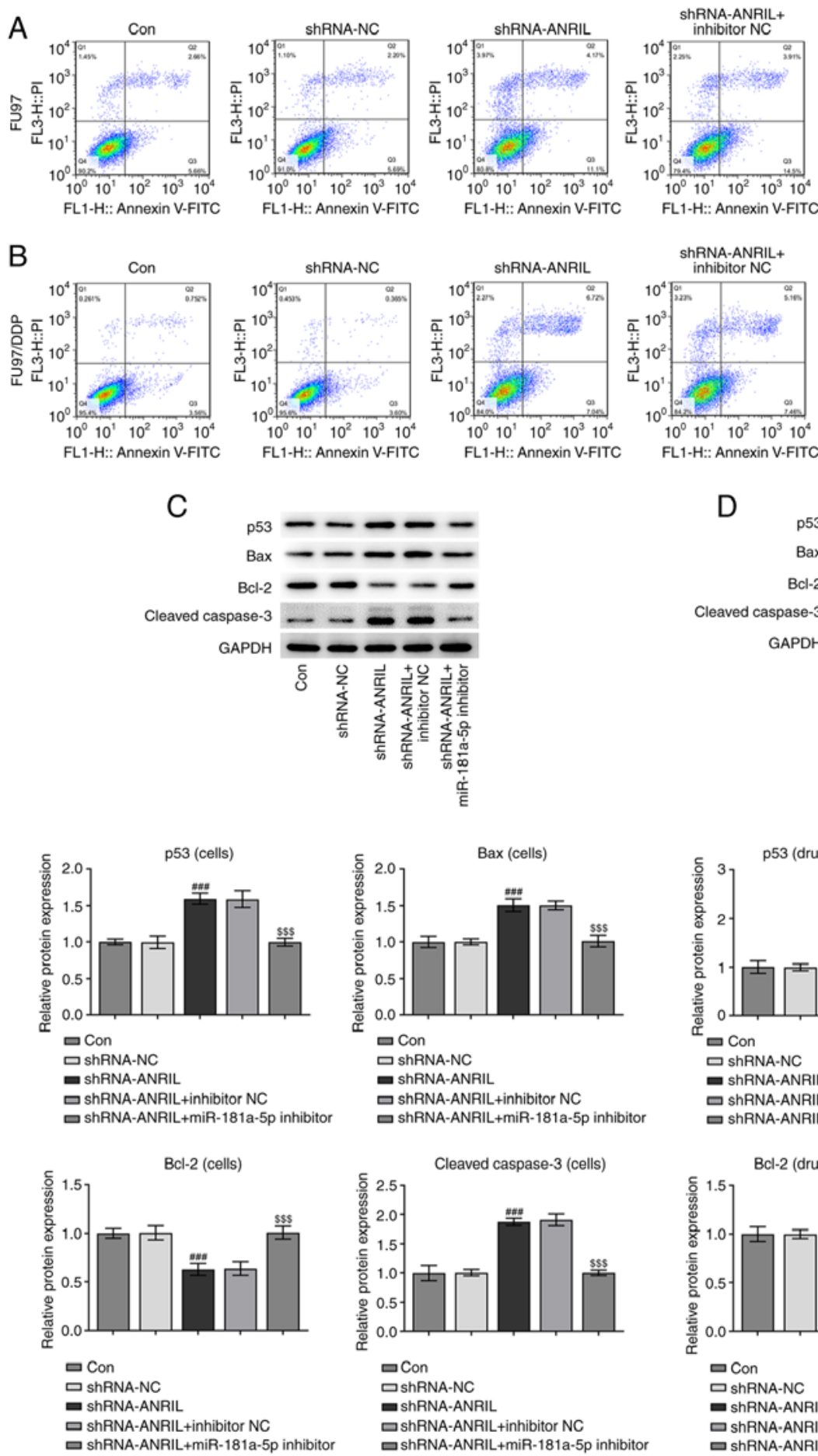
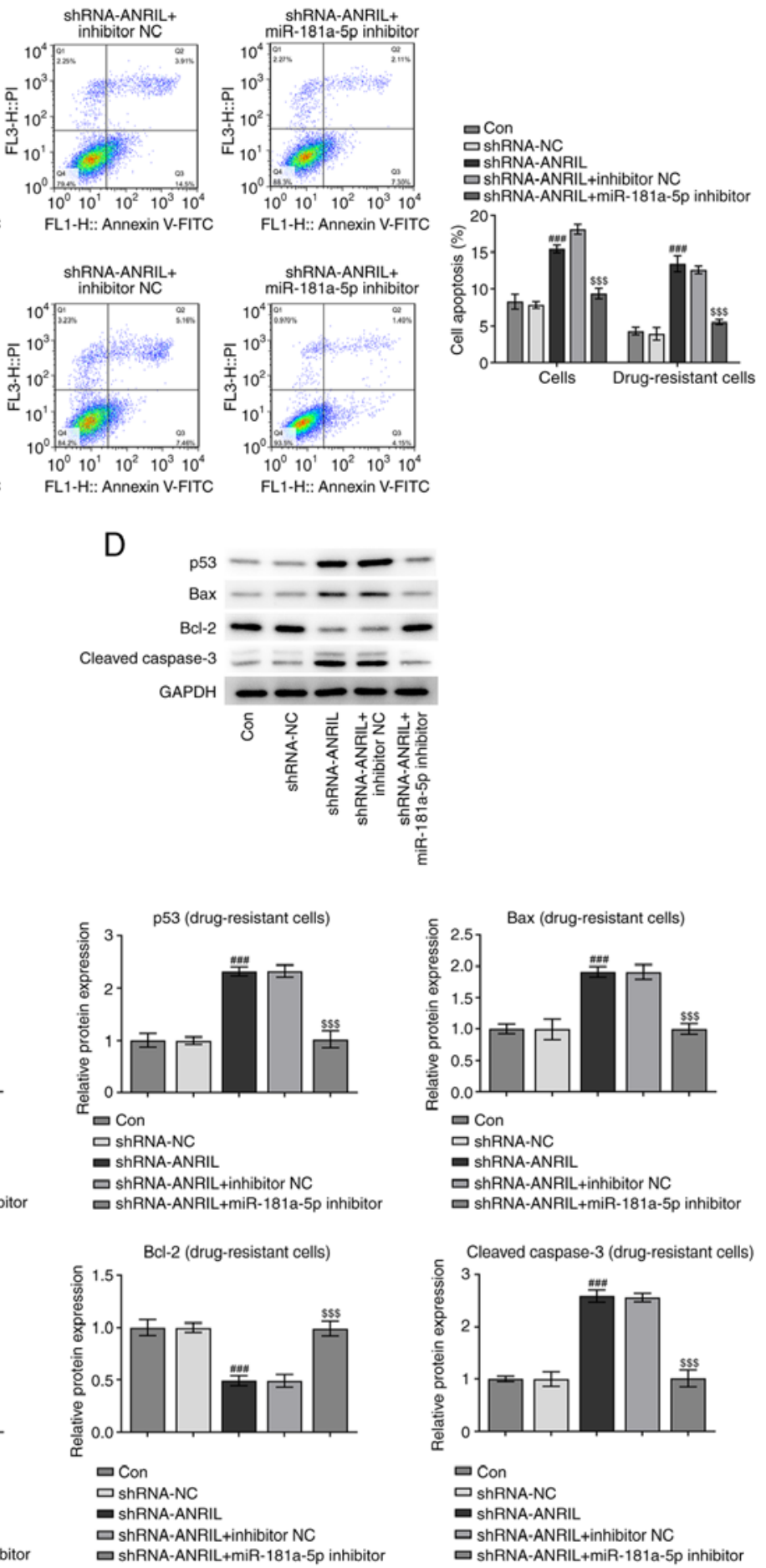

Figure 5. Apoptosis of FU97 and drug-resistant cell lines. Apoptosis of (A) FU97 and (B) FU97 DDP-resistant cell lines was detected using flow cytometry. Expression of proteins related to apoptosis in (C) FU97 and (D) FU97 DDP-resistant cell lines was analyzed using western blotting. ${ }^{\# \# \# ~ P<0.001 ~ v s . ~ s h R N A-N C ; ~}$ ${ }^{\$ \$} \mathrm{P}<0.001$ vs. shRNA-ANRIL + inhibitor NC; $\mathrm{n} \geq 3$. DDP, cisplatin; shRNA, short hairpin RNA; Con, control; NC, negative control; ANRIL, CDKN2B antisense RNA 1.

associated with apoptosis. The expression levels of p53, Bax and cleaved caspase- 3 were upregulated following the transfection of cells with shRNA-ANRIL, while the expression levels of Bcl-2 were downregulated $\left({ }^{\# \# \#} \mathrm{P}<0.001\right.$; Fig. 4C). Notably, the expression levels of each protein were reversed following the co-transfection with the miR-181-5p inhibitor ${ }^{\$ \$} \mathrm{P}<0.01$ and $\left.{ }^{\$ \$ \$} \mathrm{P}<0.001\right)$. The trends in the expression levels of each protein in the DDP-resistant cell groups were similar; however, the magnitude of the changes were more notable $\left({ }^{\# \#} \mathrm{P}<0.01,{ }^{\# \# \#} \mathrm{P}<0.001,{ }^{\$ \$} \mathrm{P}<0.01\right.$ and ${ }^{\$ \$}{ }^{\$} \mathrm{P}<0.001$; Fig. 4D). Results from flow cytometry and western blotting analyses in FU97 cell lines revealed a similar overall trend to that in the HGC-27 cell line $\left({ }^{\# \#} \mathrm{P}<0.001\right.$ and ${ }^{\$ \$} \mathrm{P}<0.001$; Fig. 5A-D).

Cell cycle distribution analysis. Following the transfection of HGC-27 cells with shRNA-ANRIL, the number of cells in the $\mathrm{G}_{0} / 1$ phase was increased; however, following 
A
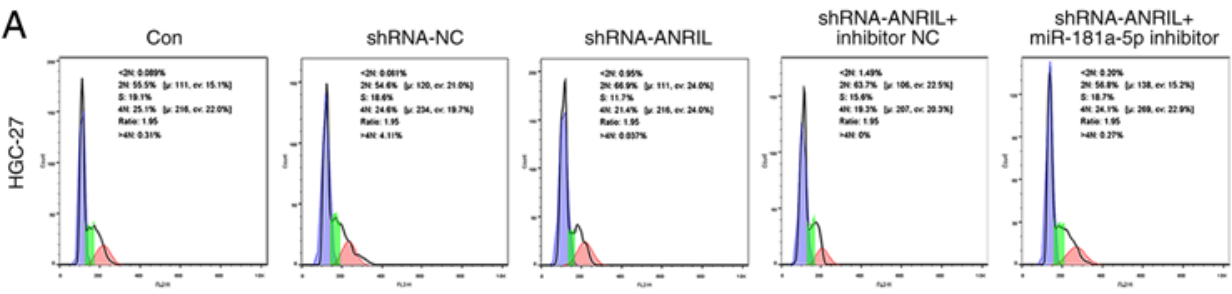

B
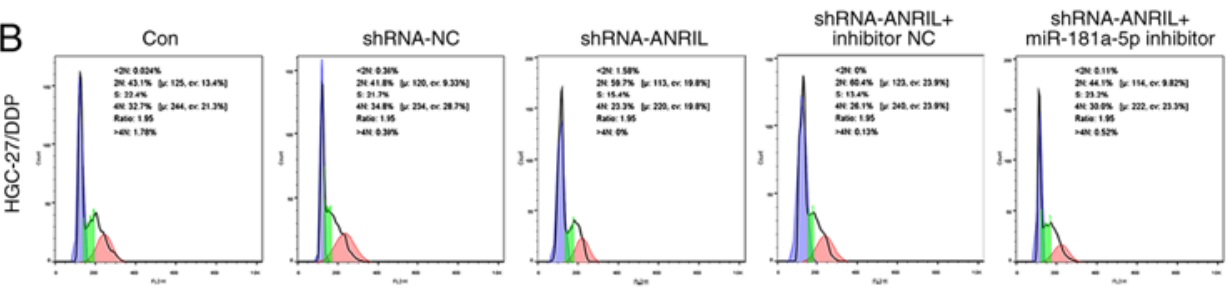

C
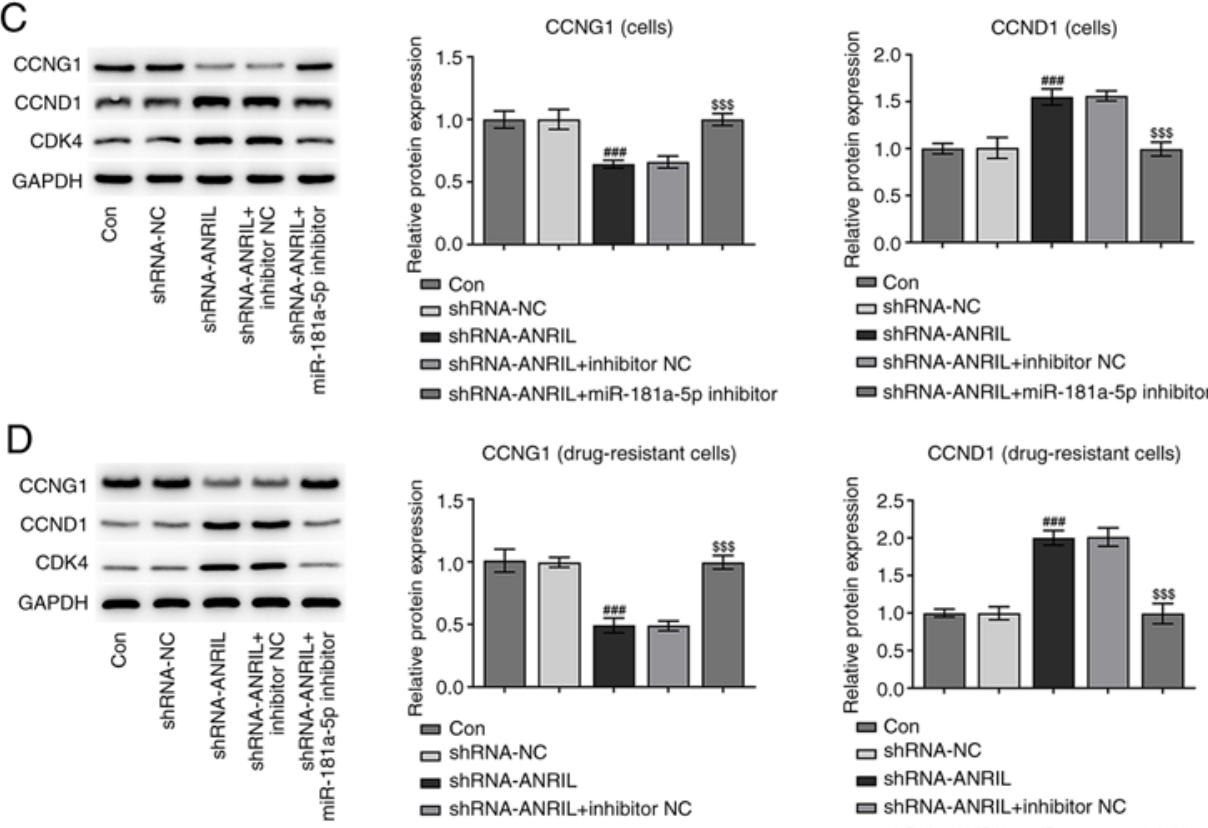

CCNG1 (drug-resistant cells)

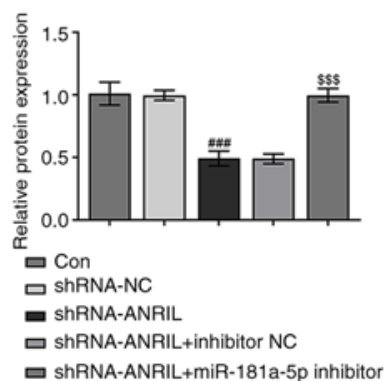

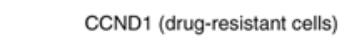

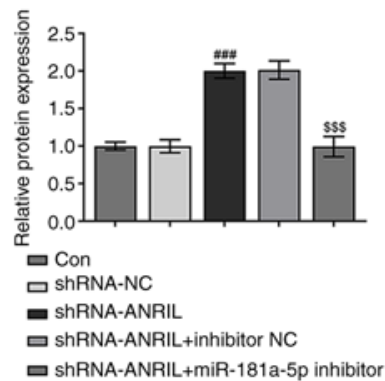

口 Con

늠NA-ANRII

shRNA-ANRIL+inhibitor NC

口 shRNA-ANRIL+miR-181a-5p inhibitor

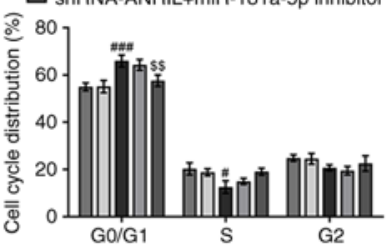

\section{$\square$ Con}

口 ShRNA-NC

- ShRNA-ANRIL

RIL+inhibitor NC

shRNA-ANRIL+miR-181a-5p inhibitor ஓ 80
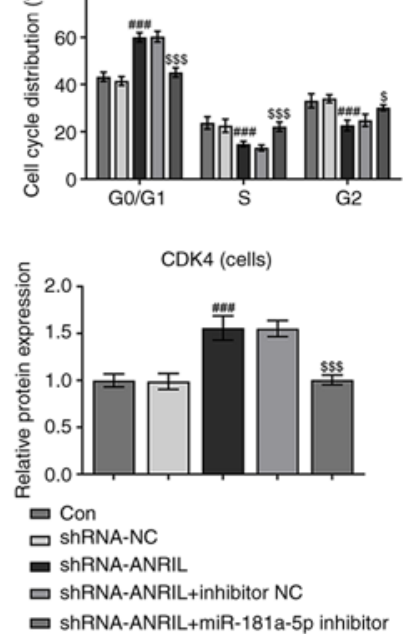

口 shRNA-ANRIL+miR-181a-5p inhibitor

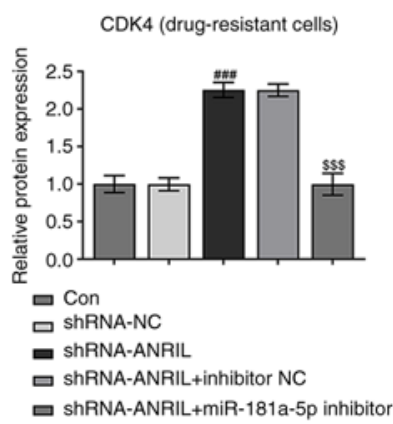

Figure 6. Cell cycle distribution of HGC-27 and drug-resistant cell lines. Cell cycle distribution of (A) HGC-27 and (B) HGC-27 DDP-resistant cell lines was analyzed using flow cytometry. Expression of proteins related to the cell cycle in (C) HGC-27 and (D) HGC-27 DDP-resistant cell lines was analyzed using western blotting. ${ }^{\#} \mathrm{P}<0.05$ and ${ }^{\# \# \#} \mathrm{P}<0.001$ vs. shRNA-NC; ${ }^{\$} \mathrm{P}<0.05,{ }^{\$ \$} \mathrm{P}<0.01$ and ${ }^{\$ \$ \$} \mathrm{P}<0.001$ vs. shRNA-ANRIL + inhibitor NC; $\mathrm{n} \geq 3$. DDP, cisplatin; shRNA, short hairpin RNA; Con, control; NC, negative control; ANRIL, CDKN2B antisense RNA 1; CCNG1, cyclin G1; CCND1, cyclin D1.

co-transfection with the miR-181a-5p inhibitor, the number of cells in the $\mathrm{G}_{0} / 1$ phase was decreased. Notably, there were fewer DDP-resistant cells in the $\mathrm{G}_{0} / 1$ phase compared with sensitive cells without transfection, and more cells in the $\mathrm{S}$ and $\mathrm{G}_{2} / \mathrm{M}$ phases. Following the transfection of DDP-resistant cells with shRNA-ANRIL, the number of cells in the $G_{0} / 1$ phase was increased, but then decreased following co-transfection with the miR-181a-5p inhibitor $\left({ }^{\#} \mathrm{P}<0.05,{ }^{\# \# \#} \mathrm{P}<0.001,{ }^{\$} \mathrm{P}<0.05,{ }^{\$ \$} \mathrm{P}<0.01\right.$ and ${ }^{\$ \$ \$} \mathrm{P}<0.001$; Fig. $6 \mathrm{~A}$ and $\mathrm{B}$ ). In addition, western blotting was used to analyze the expression levels of CCNG1, CCND1 and CDK4, which are cell cycle-related proteins. The expression levels of CCND1 and CDK4 were upregulated

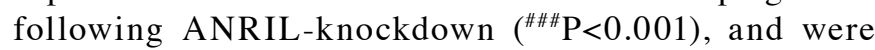
subsequently downregulated following co-transfection with the miR181a-5p inhibitor $\left({ }^{\$ \$} \mathrm{P}<0.001\right)$. The combined action of CCND1 and CDK4 promotes the progression of cells from the $G_{1}$ to $S$ phase. These results indicated that tANRIL-knockdown may induce cell cycle arrest in the $\mathrm{G}_{0} / 1$ phase, while the knockdown of miR-181a-5p may relieve cell cycle arrest (Fig. 6C). This phenomenon was more apparent in DDP-resistant cells $\left({ }^{\# \# \#} \mathrm{P}<0.001\right.$ and ${ }^{\$ \$ \$} \mathrm{P}<0.001$; Fig. 6D).

Following ANRIL-knockdown in FU97 cells, the number of cells arrested in the $\mathrm{G}_{0} /$, phase was increased, indicating that ANRIL may be involved in the progression of cells from the $\mathrm{G}_{0} /{ }_{1}$ to $\mathrm{S}$ phase. Following the knockdown of miR-181a-5p, the number of cells in the $G_{2} / M$ phase was increased and the number of cells in the $\mathrm{G}_{0} / 1$ phase was decreased, indicating that the knockdown of miR-181a-5p may promote progression to

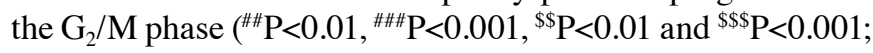



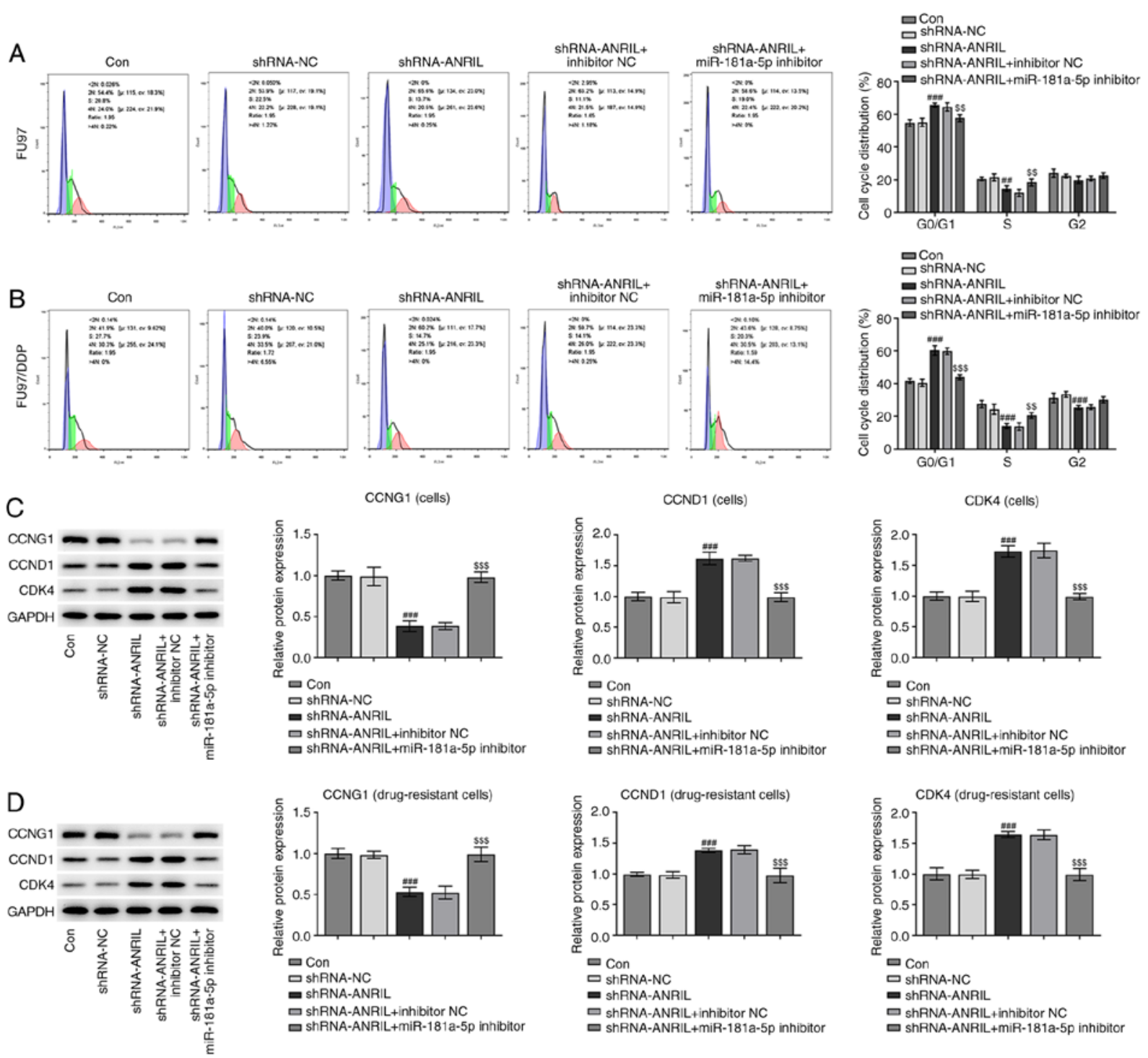

Figure 7. Cell cycle distribution of FU97 and drug-resistant cell lines. Cell cycle distribution of (A) FU97 and (B) FU97 DDP-resistant cell lines was detected using flow cytometry. Expression of proteins related to the cell cycle in (C) FU97 and (D) FU97 DDP-resistant cell lines was analyzed using western blotting. ${ }^{\# \#} \mathrm{P}<0.01$ and ${ }^{\# \# \#} \mathrm{P}<0.001$ vs. shRNA-NC group; ${ }^{\$ \$} \mathrm{P}<0.01$ and ${ }^{\$ \$ \$} \mathrm{P}<0.001$ vs. shRNA-ANRIL + inhibitor NC; $\mathrm{n} \geq 3$. DDP, cisplatin; shRNA, short hairpin RNA; Con, control; NC, negative control; ANRIL, CDKN2B antisense RNA 1; CCNG1, cyclin G1; CCND1, cyclin D1.

Fig. 7A and B). These findings are consistent with the results in HGC-27 cells. The results of western blot analysis of the expression levels of CCNG1, CCND1 and CDK4 in FU97 cells were consistent with the findings in the HGC-27 cell line $\left({ }^{(\# \# /} \mathrm{P}<0.001\right.$ and ${ }^{\$ \$ \$} \mathrm{P}<0.001$; Fig. 7C and D).

Verification of the association between miR-181a-5p and lncRNA-ANRIL or-CCNG1. The relationship between miR-181a-5p and lncRNA-ANRIL or -CCNG1 were verified using a dual luciferase reporter assay. Compared with the mimic NC-transfected cells, the relative luciferase activity of both HGC-27 and FU97 cells co-transfected with the WT-ANRIL vector and miR-181-5p mimics were significantly reduced $\left.{ }^{* * *} \mathrm{P}<0.001\right)$, while the differences in relative luciferase activitiy between cells co-transfected with the MUT-ANRIL vectors and miR-181-5p mimics or mimic NC were not statistically significant (Fig. 8A). In addition, the relative luciferase activity of cells co-transfected with the WT-CCNG1 vector and miR-181-5p mimics was also significantly reduced $\left.{ }^{(* * *} \mathrm{P}<0.001\right)$, while the differences between the relative luciferase activities of cells co-transfected with MUT-CCNG1 and miR-181-5p mimic or mimic NC were not statistically significant (Fig. 8B).

\section{Discussion}

Gastric cancer has a high incidence worldwide. For early gastric cancer, direct surgical resection is the most effective treatment option (21), while for advanced gastric cancer, chemotherapy is required following surgery (22). When the tumor adheres to the surrounding tissues, chemotherapy is the main treatment option, and it has been found to significantly improve the survival rate of patients with advanced gastric cancer (23). DDP is a commonly used chemotherapeutic drug; however, the development of drug resistance is a significant challenge that limits its clinical efficacy (24). The mechanisms underlying drug resistance in tumor cells are complex (25), thus the establishment of drug-resistant cell lines in vitro is 
A

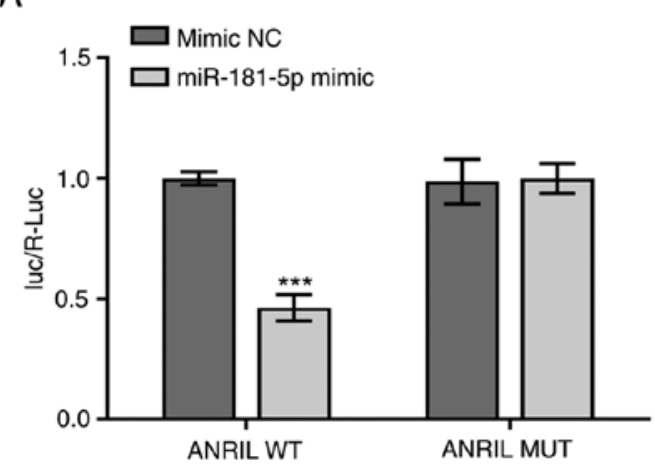

B

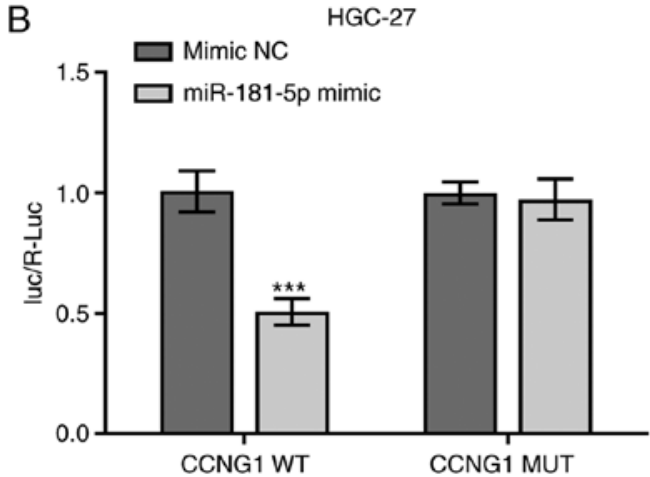

HGC-27
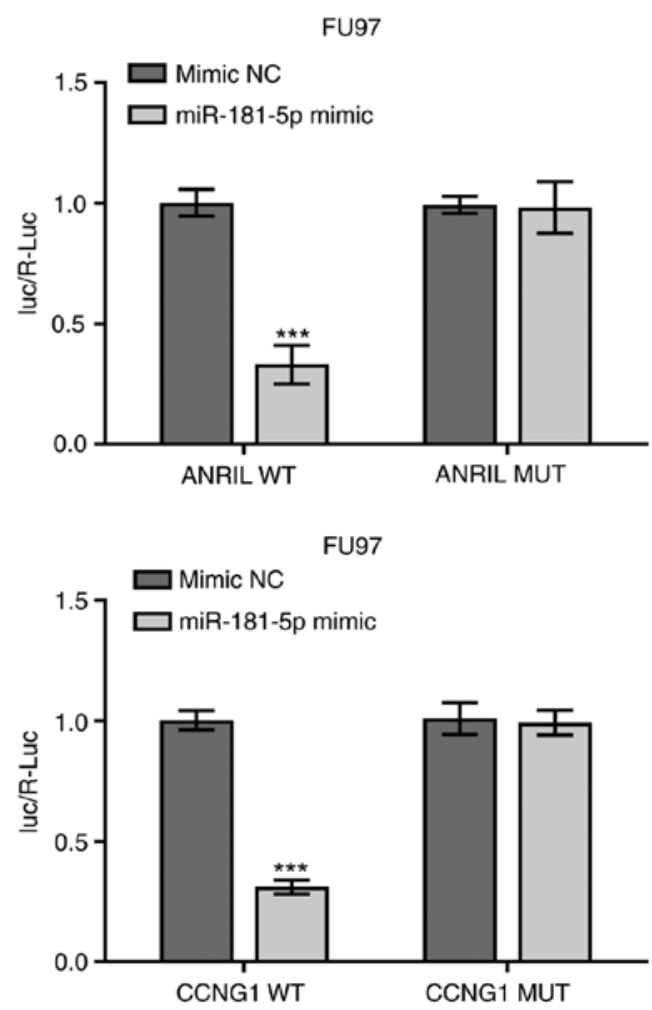

Figure 8. Association between miR-181a-5p and lncRNA ANRIL or CCNG1. Relationship between 1ncRNA ANRIL and (A) miR-181a-5p or (B) CCNG1 in HGC-27 and FU97 cell lines was detected using a dual luciferase reporter assay. ${ }^{* * *} \mathrm{P}<0.001 \mathrm{vs.} \mathrm{mimic} \mathrm{NC;} \geq 3$. miR, microRNA; lncRNA, long non-coding RNA; ANRIL, CDKN2B antisense RNA 1; CCNG1, cyclin G1; NC, negative control.

a prerequisite for studying the biological changes of tumor cells. In the present study, a stepwise continuous selection method was used to construct DDP-resistant gastric cancer cell lines.

Previous studies reported that the expression levels of CCNG1 were significantly upregulated in a number of tumor tissue types, which promoted tumor cell proliferation $(26,27)$. The dysregulated expression of CCNG1 resulted in abnormal cell cycle regulation, thereby affecting tumor occurrence and development (28). Zhang et al (29) analyzed the association between ANRIL and clinicopathological features and prognosis in cervical cancer by determining the expression of ANRIL in cervical cancer tissues and cell lines. The results revealed that patients with high ANRIL expression had advanced FIGO stage, lymph node metastasis and poor overall survival. In addition, the knockdown of ANRIL expression inhibited cellular proliferation, migration and the occurrence of cervical cancer.

In the present study, following induction with DDP, the expression levels of CCNG1, ANRIL and miR-181a-5p determined to confirm the successful construction of drug-resistant cells. The results of RT-qPCR analysis indicated that the expression levels of CCNG1 and ANRIL were significantly upregulated in drug-resistant compared with sensitive cell lines. As for miR-181-5p, the expression levels in sensitive cells were somewhat inconsistent, and multiple studies have reported that the role of miR-181-5p in gastric cancer is controversial. For example, Chen et al (30) demonstrated that miR-181a-5p expression levels were upregulated in gastric cancer, and that the overexpression of miR-181a-5p promoted cellular proliferation. Furthermore, Lu et al (31) reported that knocking down metastasis associated lung adenocarcinoma 1 (MALAT1) inhibited proliferation and promoted the apoptosis of MGC-803 cells. The overexpression of miR-181a-5p exhibited similar effects to MALAT1-knockdown. In addition, Ghaedi et al (32) did not identify any significant differences in miR-181a-5p expression between patients with gastric cancer and healthy participants. However, these findings do not affect those of the present study on drug-resistant cell lines, because miR-181a-5p was found to be downregulated in all constructed drug-resistant cell lines. In the current study, HGC-27 and FU97 cell lines were selected for subsequent experiments.

With the development of high-throughput sequencing technology, the roles of lncRNAs have attracted the attention of numerous research groups. Previous studies have found that lncRNAs have a high degree of tissue specificity, and are involved in a variety of tumor cells processes (33). ANRIL has been associated with the development of malignant tumor types, suggesting its significant potential in cancer $(11,12)$. However, the current underlying mechanism of ANRILremains undetermined, and further investigation is required to establish its function. To elucidate the role of ANRIL in sensitive and drug-resistant cell lines, cells were transfected with an miR-181a-5p inhibitor and shRNA-ANRIL vector, and transfection efficiency was determined using RT-qPCR. A CCK- 8 assay was also used to detect the proliferation and sensitivity of non-resistant and DDP-resistant cells to DDP. Following ANRIL-knockdown in drug-resistant cells, the current results suggested that cellular proliferation was significantly decreased following $24 \mathrm{~h}$ of culture, indicating that ANRIL may promote the proliferation of gastric cancer cells. Compared with the control cells, the 
sensitivity of drug-resistant cell lines to DDP was markedly increased. To the best of our knowledge, only one previous study has studied the role of ANRIL in drug-resistant gastric cancer cells (34), and the downstream regulation of ANRIL has not been studied. In the present study, using bioinformatics analysis via ENCORI database, miR-181a-5p was predicted to share a targeting relationship with ANRIL. miR-181a-5p was also found to inhibit the proliferation of drug-resistant cells and enhance sensitivity to DDP. To the best of our knowledge, these findings have not been reported by others.

Based on the aforementioned findings, flow cytometry was used to investigate the effect of ANRIL and miR-181a-5p on apoptosis and cell cycle distribution. The results of the flow cytometric apoptosis analysis were consistent with those of the CCK-8 assay. Furthermore, ANRIL-knockdown was found to promote cell cycle arrest, while following the knockdown of miR-181a-5p, cell cycle arrest was alleviated. These findings suggested that ANRIL and miR-181-5p may both be involved in the cell cycle. Subsequently, western blotting was used to detect the expression levels of proteins related to apoptosis and the cell cycle, which verified the results of the flow cytometric experiments. Finally, the relationships between miR-181a-5p and ANRIL or CCNG1 were verified using dual luciferase reporter assays. The binding of miR-181a-5p to $1 n c R N A$ ANRIL and CCNG1 was investigated separately, and binding interactions were identified between both.

In conclusion, the results of the present study suggested that the knockdown of ANRIL expression may inhibit the proliferation of gastric cancer cells, promote apoptosis and induce cell cycle arrest. In addition, its downstream target, miR-181a-5p, was found to not only reverse the effects of ANRIL (especially in drug-resistant cells), thereby playing a tumor-suppressive role, but also to regulate the function of the target gene, CCNG1. To the best of our knowledge, the present study is the first to investigate the downstream regulation of ANRIL in gastric cancer. The discovery that miR-181a-5p improves the sensitivity of drug-resistant cells to DDP may provide insights into novel treatments for drug-resistant gastric cancer. However, only in vitro experiments were conducted, and further in vivo investigation is required to validate the present findings.

\section{Acknowledgements}

Not applicable.

\section{Funding}

The present study was supported by the Ningbo Natural Science Foundation (grant no. 2019A610337).

\section{Availability of data and materials}

The datasets used and/or analyzed during the current study are available from the corresponding author on reasonable request.

\section{Authors' contributions}

$\mathrm{XH}$ and TL designed the study, and performed the experiments alongside CY and YSW. XT wrote the manuscript and analyzed the data alongside YW. TZ conceived the study, supervised the experiments and revised the manuscript for important intellectual content. All authors read and approved the final manuscript. XH and $\mathrm{TZ}$ confirm the authenticity of all the raw data.

\section{Ethics approval and consent to participate}

Not applicable.

\section{Patient consent for publication}

Not applicable.

\section{Competing interests}

The authors declare that they have no competing interests.

\section{References}

1. Taft RJ, Pheasant $M$ and Mattick JS: The relationship between non-protein-coding DNA and eukaryotic complexity. Bioessays 29: 288-299, 2007.

2. Iyer MK, Niknafs YS, Malik R, Singhal U, Sahu A, Hosono Y, Barrette TR, Prensner JR, Evans JR, Zhao S, et al: The landscape of long noncoding RNAs in the human transcriptome. Nat Genet 47: 199-208, 2015.

3. Fidler IJ, Yano S, Zhang RD, Fujimaki T and Bucana CD: The seed and soil hypothesis: Vascularisation and brain metastases. Lancet Oncol 3: 53-57, 2002.

4. Ellis LM and Hicklin DJ: VEGF-targeted therapy: Mechanisms of anti-tumour activity. Nat Rev Cancer 8: 579-591, 2008.

5. Wang C, Wen Z, Xie J, Zhao Y, Zhao L, Zhang S, Liu Y, Xue Y and Shi M: MACC1 mediates chemotherapy sensitivity of 5-FU and cisplatin via regulating MCT1 expression in gastric cancer. Biochem Biophys Res Commun 485: 665-671, 2017.

6. Hombach S and Kretz M: Non-coding RNAs: Classification, biology and functioning. Adv Exp Med Biol 937: 3-17, 2016.

7. Bhan A and Mandal SS: Long noncoding RNAs: Emerging stars in gene regulation, epigenetics and human disease. ChemMedChem 9: 1932-1956, 2014.

8. Yap KL, Li S, Muñoz-Cabello AM, Raguz S, Zeng L, Mujtaba S, Gil J, Walsh MJ and Zhou MM: Molecular interplay of the noncoding RNA ANRIL and methylated histone H3 lysine 27 by polycomb CBX7 in transcriptional silencing of INK4a. Mol Cell 38: 662-674, 2010.

9. Tachibana I, Smith JS, Sato K, Hosek SM, Kimmel DW and Jenkins RB: Investigation of germline PTEN, p53, p16(INK4A)/p14(ARF), and CDK4 alterations in familial glioma. Am J Med Genet 92: 136-141, 2000.

10. Shen XH, Qi P and Du X: Long non-coding RNAs in cancer invasion and metastasis. Mod Pathol 28: 4-13, 2015.

11. Nie FQ, Sun M, Yang JS, Xie M, Xu TP, Xia R, Liu YW, Liu XH, Zhang EB, Lu KH and Shu YQ: Long noncoding RNA ANRIL promotes non-small cell lung cancer cell proliferation and inhibits apoptosis by silencing KLF2 and P21 expression. Mol Cancer Ther 14: 268-277, 2015.

12. Chen D, Zhang Z, Mao C, Zhou Y, Yu L, Yin Y, Wu S, Mou X and Zhu Y: ANRIL inhibits p15(INK4b) through the TGF $\beta 1$ signaling pathway in human esophageal squamous cell carcinoma. Cell Immunol 289: 91-96, 2014.

13. Arita T, Ichikawa D, Konishi H, Komatsu S, Shiozaki A, Shoda K, Kawaguchi T, Hirajima S, Nagata H, Kubota T, et al: Circulating long non-coding RNAs in plasma of patients with gastric cancer. Anticancer Res 33: 3185-3193, 2013.

14. Rupaimoole R and Slack FJ: MicroRNA therapeutics: Towards a new era for the management of cancer and other diseases. Nat Rev Drug Discov 16: 203-222, 2017.

15. Lin F, Li Y, Yan S, Liu S, Qian W, Shen D, Lin Q and Mao W: MicroRNA-181a inhibits tumor proliferation, invasiveness, and metastasis and is downregulated in gastric cancer. Oncol Res 22: 75-84, 2015.

16. Livak KJ and Schmittgen TD: Analysis of relative gene expression data using real-time quantitative PCR and the 2(-Delta Delta C(T)) method. Methods 25: 402-408, 2001. 
17. Li JH, Liu S, Zhou H, Qu LH and Yang JH: starBase v2.0: Decoding miRNA-ceRNA, miRNA-ncRNA and protein-RNA interaction networks from large-scale CLIP-Seq data. Nucleic Acids Res 42 (Database Issue): D92-D97, 2014.

18. Lewis BP, Shih IH, Jones-Rhoades MW, Bartel DP and Burge CB Prediction of mammalian microRNA targets. Cell 115: 787-798, 2003.

19. Krek A, Grün D, Poy MN, Wolf R, Rosenberg L, Epstein EJ, MacMenamin P, da Piedade I, Gunsalus KC, Stoffel M and Rajewsky N: Combinatorial microRNA target predictions. Nat Genet 37: 495-500, 2005.

20. Enright AJ, John B, Gaul U, Tuschl T, Sander C and Marks DS MicroRNA targets in Drosophila. Genome Biol 5: R1, 2003.

21. Oda I, Shimazu T, Ono H, Tanabe S, Iishi H, Kondo H and Ninomiya M: Design of Japanese multicenter prospective cohort study of endoscopic resection for early gastric cancer using web registry (J-WEB/EGC). Gastric Cancer 15: 451-454, 2012.

22. Jim MA, Pinheiro PS, Carreira H, Espey DK, Wiggins CL and Weir HK: Stomach cancer survival in the United States by race and stage (2001-2009): Findings from the CONCORD-2 study. Cancer 123 (Suppl 24): S4994-S5013, 2017.

23. Song Z, Wu Y, Yang J, Yang D and Fang X: Progress in the treatment of advanced gastric cancer. Tumour Biol 39 : 1010428317714626,2017

24. Li Y, Lv S, Ning H, Li K, Zhou X, Xv H and Wen H: Down-regulation of CASC2 contributes to cisplatin resistance in gastric cancer by sponging miR-19a. Biomed Pharmacother 108: $1775-1782,2018$

25. Wei L, Sun J, Zhang N, Zheng Y, Wang X, Lv L, Liu J, Xu Y, Shen $Y$ and Yang M: Noncoding RNAs in gastric cancer: Implications for drug resistance. Mol Cancer 19: 62, 2020.

26. Xu Y, Zhang Q, Miao C, Dongol S, Li Y, Jin C, Dong R, Li Y, Yang X and Kong B: CCNG1 (Cyclin G1) regulation by mutant-P53 via induction of Notch3 expression promotes high-grade serous ovarian cancer (HGSOC) tumorigenesis and progression. Cancer Med 8: 351-362, 2019.
27. Han H, Zhang Z, Yang X, Yang W, Xue C and Cao X: miR-23b suppresses lung carcinoma cell proliferation through CCNG1. Oncol Lett 16: 4317-4324, 2018.

28. Ye XX, Liu CB, Chen JY, Tao BH and Zhi-Yi C: The expression of cyclin $\mathrm{G}$ in nasopharyngeal carcinoma and its significance. Clin Exp Med 12: 21-24, 2012.

29. Zhang D, Sun G, Zhang H, Tian J and Li Y: Long non-coding RNA ANRIL indicates a poor prognosis of cervical cancer and promotes carcinogenesis via PI3K/Akt pathways. Biomed Pharmacother 85: 511-516, 2017.

30. Chen G, Shen ZL, Wang L, Lv CY, Huang XE and Zhou RP: hsa-miR-181a-5p expression and effects on cell proliferation in gastric cancer. Asian Pac J Cancer Prev 14: 3871-3875, 2013.

31. Lu Z, Luo T, Pang T, Du Z, Yin X, Cui H, Fang G and Xue X: MALAT1 promotes gastric adenocarcinoma through the MALAT1/miR-181a-5p/AKT3 axis. Open Biol 9: 190095, 2019.

32. Ghaedi H, Mozaffari MAN, Salehi Z, Ghasemi H, Zadian SS, Alipoor S, Hadianpour S and Alipoor B: Co-expression profiling of plasma miRNAs and long noncoding RNAs in gastric cancer patients. Gene 687: 135-142, 2019.

33. Capizzi M, Strappazzon F, Cianfanelli V, Papaleo E and Cecconi F: MIR7-3HG, a MYC-dependent modulator of cell proliferation, inhibits autophagy by a regulatory loop involving AMBRA1. Autophagy 13: 554-566, 2017.

34. Lan WG, Xu DH, Xu C, Ding CL, Ning FL, Zhou YL, Ma LB, Liu CM and Han X: Silencing of long non-coding RNA ANRIL inhibits the development of multidrug resistance in gastric cancer cells. Oncol Rep 36: 263-270, 2016.

This work is licensed under a Creative Commons Attribution-NonCommercial-NoDerivatives 4.0 International (CC BY-NC-ND 4.0) License. 